\title{
João Cabral de Melo Neto: o arquiteto das palavras
}

Fabrício Lima Oliveira (IC/UEFS). ${ }^{1}$

Roberval Alves Pereira (Orientador/UEFS). ${ }^{2}$

RESUMO: O presente artigo busca refletir a respeito da poesia do poeta João Cabral de Melo Neto, principalmente o livro Quardena (1956-1959), o qual apresenta uma delicada e profunda reflexão lírico-filosófica-amorosa sobre o corpo feminino e o Nordeste. Este texto versa ainda pelas veredas da multifacetada poesia mostrando, de diversas formas e em muitas dimensões, a riqueza que há no processo construtivo da poesia cabralina. Nesse sentido, para dar conta disso tudo, o poeta assevera o domínio de várias áreas de conhecimento e a habilidade de encontrar soluções formais para os mais diversos estorvos existenciais encenados em seus poemas.

PLAVRAS-CHAVE: Poesia; Estética; Contemporaneidade.

\footnotetext{
${ }^{1}$ Graduando do Curso de Licenciatura em Letras Vernáculas na Universidade Estadual de Feira de Santana - UEFS, e-mail: oliverletras01@gmail.com
}

\footnotetext{
${ }^{2}$ Professor Orientador: Dr. em Teoria e História Literária pela Universidade Estadual de Campinas, Professor Pleno de Literatura na Universidade Estadual de Feira de Santana - UEFS, e-mail: robervalpereyr@gmail.com
} 


\section{INTRODUÇÃO}

O poeta João Cabral de Melo Neto apresenta em Quardena (1956-1959) uma delicada e profunda reflexão lírico-filosófica-amorosa acerca do corpo feminino e do Nordeste. Sua multifacetada poesia mostra, de diversas formas e em muitas dimensões, a riqueza que há no processo construtivo. O poeta assevera o domínio de várias áreas de conhecimento e a habilidade de encontrar soluções formais para os mais diversos estorvos existenciais encenados em seus poemas. Neste sentido, não hesita em lançar mão, por exemplo, do mais sincero lirismo, ou do empenho estético, da criação de uma linguagem diferente e desconcertante lhe é característico, muitas vezes obtida pela capacidade (precisa) de fazer uso da metáfora, que põe em cheque a simples racionalidade. Desse modo, João Cabral não perde jamais de vista a extensão estética da linguagem, evidenciada através do uso (e da combinação) sempre apropriada e surpreendente da metrificação, do esquema rítmico, da imagem e da musicalidade.

Em seguida, passarei a considerar alguns poemas de João Cabral de Melo Neto publicados em A educação pela pedra e outros poemas, reunião de livros editados em 2008 pela ALFAGUARA. Nesses poemas mostrarei alguns aspectos da poesia do autor, dentre eles a novidade temática: a mulher, tendo em vista, por ora (uma vez que no campo de um discreto artigo não poderei dar conta do que aqui se verifica acerca da produção poética do autor), as colocações feitas acima neste sentido. Portanto, neste artigo, tentarei somente oferecer uma amostra do que desejo, em projeto futuro, trabalhar em $A$ educação pela pedra e outros poemas, de João Cabral de Melo Neto.

\section{MEDITAÇÕES}

Tomarei inicialmente o poema intitulado "Estudos para uma bailadora andaluza" (CABRAL, 1960) no qual a temática gira (de modo sutil e erótico) em 
torno da figura da mulher de natureza faminta a qual é comparada à espiga, fogo e livro. Eis o poema:

\author{
Dir-se-ia, quando aparece \\ dançando por siguiriyas, \\ que com a imagem do fogo \\ inteira se identifica. \\ Sua dança sempre acaba \\ igual que como começa, \\ tal esses livros de iguais \\ coberta e contracoberta: \\ com a mesma posição \\ como que talhada em pedra: \\ um momento está estátua, \\ desafiante, à espera. [...] \\ Na sua dança se assiste \\ como ao processo da espiga: \\ verde, envolvida de pelha; \\ madura, quase despida.
}

Verifica-se que o poema é composto de seis cantos, que o poeta intitula de estudos, haja vista a afinidade com delineações de pinturas, tal como a proposta imagística que guia o texto. Nenhum poema é neutro: as experiências literárias vividas por João Cabral de Melo Neto - na Espanha - estão impregnadas nos versos, afora o ritmo inconcebível que o escritor atinge no poema, levando a leitura num compasso lírico-místico. Cabral ama a cultura hispânica, o canto, a dança, as bailadoras, as touradas. Assim sendo, preserva, de forma veemente, os vestígios de uma linguagem sugestiva, em que a mulher e a natureza se unem, no cumprimento do que Emil Staiger, no livro Conceitos fundamentais da poética (1970), chama de "um-no-outro", expressão que usa para definir o estado lírico por primazia. Cabral valoriza o encanto de cada palavra definindo um espaço preciso para colocá-las dentro do poema. 
O poema "Paisagem pelo telefone" (CABRAL, 1960), traz à tona um eulírico sentimental que deseja tornar sólido aquilo que é líquido. Cabral representa (através da redondilha maior) o discurso das pessoas, atentando-se para a métrica e para sintaxe, obedecendo ao máximo a quebra que há em cada verso, e, não obstante, introduzindo - em uma linha e noutra - sílabas fortes, criando, assim, uma lírica que espanta e que chama a atenção para o próximo salto. A dicção cabralina é feita "do dentro que vai trabalhando o fora" (BOSI, 1983). Verifica-se ainda que o panorama é bem delineado: o poeta sonha com Pernambuco através da voz da mulher amada ao telefone. João Cabral de Melo Neto inventou uma nova forma de fazer poesia. Suas palavras parecem surgir como "um dentro de nós em oposição a um mundo fora de nós" (BOSI, 1983).:

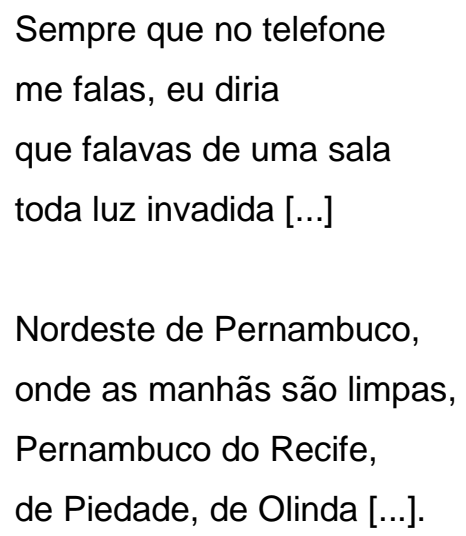

Pelos olhos de Octavio Paz, ninguém pode escapar da crença no poder mágico das palavras. A poesia cabralina estabelece a magia e o poder da linguagem em perspectivas e dimensões distintas. No poema "Cemitério paraibano (Entre Flores e Princesa)", o poeta instaura um ambiente restrito às feições oníricas e ao cenário local, em que o domínio do cenário fúnebre nos coloca numa situação de grande medo e solidão dentro de uma casa pequena. Entende-se, inclusive, que a identificação exata do espaço apresenta múltiplas diferenças entre as regiões mais favorecidas - financeiramente - e as menos favorecidas. Por fim, o poeta retrata ainda o cemitério como a casa dos mortos deste lugar: 
Uma casa é o cemitério

dos mortos deste lugar.

A casa só, sem puxada,

e casa de um só andar.

E da casa só o recinto

entre a taipa lateral.

Nunca se usou o jardim;

Muito menos, o quintal.

E casa pequena: própria menos a hotel que a pensão;

pois os inquilinos cabem

no cemitério saguão,

os poucos que, por aqui

recusaram o privilégio

de cemitérios cidades

em cidades cemitérios.

Já em "A mulher e a casa" (p. 57-58), o poeta nos apresenta um poema lúdico cuja função é seduzir o leitor através de sua plácida elegância. Huizinga (1980, p. 133) entende que "a função do poeta continua na esfera lúdica em que nasceu". Nesse sentido, João Cabral se dirige à figura feminina como se esta fosse uma casa. O vocábulo "dentro" e o "ritmo" são primordiais para a riqueza formal e para a lírica; mas, para tanto, o poeta se vale da linguagem repleta de sentimentos e emoções. Salientando, desse modo, o poder de sedução que habita o interior da mulher, produzindo o efeito lírico mais oportuno. Eis o poema:

\footnotetext{
Tua sedução é menos

de mulher do que de casa;

pois vem de como é por dentro

ou por detrás da fachada.
} 
Seduz pelo que é dentro,

ou será, quando seabra;

pelo que pode ser dentro

de suas paredes fechadas;

os quais sugerindo ao homem

estâncias aconchegadas,

paredes bem revestidas

ou recessos bons de cavas.

"A palavra seda" (p. 65-66), transporta o leitor a um macrocosmo em que 0 chão da poesia é suave, de grande delicadeza e doce. As palavras brotam feito flores a nascer de um jarro. A sensibilidade de João Cabral de Melo Neto não o deixou contemplar a seda apenas como mero tecido, porém, sim, como uma musa que (en)canta e enfeita. Nesse sentido, o poeta se apresenta como o arquiteto das palavras inaugurando uma espécie de tributo à mulher. Cabe então reafirmar que o processo de criação em João Cabral de Melo Neto dá-se basicamente sob a aba de fazer da palavra não um veículo de exaltação dos sentimentos pessoais ou do acaso, mas da atmosfera e do humano:

\footnotetext{
A atmosfera que te envolve atinge tais atmosferas que transforma muitas coisas que te concernem, ou cercam.

E como as coisas, palavras impossíveis de poema: exemplo, a palavra ouro, e até este poema, seda.

É certo que tua pessoa não faz dormir, mas desperta; nem é sedante, palavra derivada da de seda. E é certo que a superfície de tua pessoa externa,
} 
de tua pele e de tudo

isso que em ti se tateia,

nada tem da superfície

luxuosa, falsa, acadêmica,

de uma superfície quando

se diz que ela é "como seda".

Mas em ti, em algum ponto,

talvez fora de ti mesma,

talvez mesmo no ambiente

que retesas quando chegas,

há algo de muscular,

de animal, carnal, pantera,

de felino, da substância

felina, ou sua maneira,

de animal, de animalmente,

de cru, de cruel, de crueza, que sob a palavra gasta

persiste na coisa seda.

No poema "Paisagens com cupim" (p. 47-53), João Cabral de Melo Neto, de forma bem descritiva, separa o poema em dez estrofes. Nas linhas primeiras, descreve (limpo, exato e melodicamente) a cidade de Recife. A função do poeta, neste poema, é asseverar a catástrofe que a sociedade do cupim provoca nos solos das cidades que cercam a capital pernambucana. Cabral evidencia uma linguagem mordaz, em que a evocação da natureza ("os bichos do mar, seu cupim"), anuncia a força da linguagem e profundidade crítica: "Olinda não usa cimento. / Usa um tijolo farelento. / Mesmo com tanta geometria, / Olinda é já de alvenaria [...]". O recurso da rima ajuda no entendimento do espaço e nas formas. Assim, conteúdo e forma se fundem, produzindo o efeito lírico mais oportuno e repleto de briga e significado. Na visão de Paul Valéry (2007, p. 203), no momento da criação, o poeta briga com a matéria verbal, "obrigado a especular sobre o som e o sentido ao mesmo tempo, para satisfazer não somente o harmônico, o período musical, mas também as condições intelectuais e estéticas variadas, sem contar as regras convencionais". É importante observar a riqueza 
na sonoridade das palavras cabralina. O jogo que é feito com a cidade de Recife, uma cidade que "sabe cair: limpo e exato", sem dó. A musicalidade contribui para o surgimento de um movimento arquitetado, em que blocos de cimento caem e forma uma barricada a fim de proteger a cidade contra o mar e o cupim. Nesse sentido, o poeta Cabral apresenta uma apurada reflexão sobre a cidade de Recife através do poder da linguagem. Por isso, para Ezra Pound (1934, p. 32), "literatura é linguagem carregada de significado". Neste sentido, Cabral não hesita em apresentar, por exemplo, o lirismo, ou, ao contrário, o exagero, o grotesco, a ironia da cidade recifense, sem deixar de lado jamais a dimensão estética da linguagem, evidenciada através da rima e da musicalidade, tratandoas de modo tão profundo e particular. Eis o poema:

\footnotetext{
O Recife cai sobre o mar sem dele se contaminar.

$O$ recife cai em cidade, cai contra o mar, contra: em laje.
}

As vilas entre coqueirais

(as muitas Itamaracás)

mais que as corrói o tal cupim:

ele mesmo as modela assim.

São aldeias leves de palha,

plantadas raso sobre a praia

com os escavados materiais

que o cupim trabalha e o mar traz.

Menos da terra que do mar:

dos cupins que ele faz medrar

e dão a tudo a carne leve

que o mar quer nas coisas que leve.

Tomarei agora o poema intitulado "Cemitério pernambucano (Floresta do Navio)" (p. 54) em que a temática gira em torno da morte através de um sujeito poético que com ela (a morte) detém uma retórica de forma dinâmica e 
intensamente lírica. "Literatura é novidade que permanece novidade", Ezra Pound (1934, p. 33); é justamente esta novidade que demarca o espaço regional do qual o poeta fala. Por meio de uma linguagem clara e coesa as exposições feitas pelo poeta admitem que sejam identificadas as regiões das quais ele trata no poema. Desse modo, deduz-se que a identificação precisa do espaço não atua como empecilho, possibilitando, assim, a distinção entre regiões mais e menos favorecidas. João Cabral de Melo Neto poetizou, com ênfase, o Nordeste, seu cenário de ópera, o sertão e suas palavras esdrúxulas:

\author{
Antes se ver Floresta \\ se vê uma Constantinopla \\ complicada com barroco, \\ gótico e cenário de ópera. \\ É o cemitério. E esse estuque \\ tão retórico e florido \\ é o estilo doutor, do gosto \\ do orador e do político, \\ de um político orador \\ que, em vez de frase, com tumbas \\ quis compor esta oração \\ toda em palavra esdrúxulas, \\ esdrúxula, na folha plana \\ do Sertão, onde, desnuda, \\ a vida não ora, fala, \\ e com palavras agudas.
}

No poema "Litoral de Pernambuco" (p. 55-56), o poeta dá ênfase, na primeira estrofe, à relação do mar com a terra: ("O mar se estende pela terra / em ondas que se revezam / e se vão desdobrando até / ondas secas de outras marés [...]", as palavras fluem seguindo um ritmo de vaivém como se as ondas estivessem passando por um processo de ressaca e, por conseguinte, invadissem os mangues, os canaviais e o campo raso do horizonte. Neste 
poema, tudo se torna uma extensão do mar a semear a tranquilidade dos versos do poeta "[...] como se tudo fosse o mar / em mais ondas a desdobrar / a mesma natureza rente / de um verde ácido e higiene [...]" Segundo Rollo May (1975, p. 30), "os artistas são em geral pessoas tranquilas, preocupadas com suas visões e imagens interiores". A tranquilidade do mar personifica o homem e apresenta, sob o sol nordestino, uma apurada reflexão filosófica acerca do que este rio devassa: "tudo sob um céu mineral / que preside em pedra, imparcial, / e que devassa tudo ali: / mesmo os grotões onde parir". Aqui, numa perspectiva multifacetada, Cabral poesia retrata, de múltiplas maneiras, a instabilidade e a fragilidade da condição humana perante a natureza em constante mudança. Para dar conta de tudo isso, o poeta necessita de um amplo domínio de muitas áreas do saber a fim de encontrar soluções para as mais diversas situações existenciais deste universo. Neste sentido, o poeta não lança mão do lirismo do verde da natureza ácida, dos rios e das ondas secas, gerando estética e musicalidade muito oportunos.

Verifica-se no imenso poema "O motorneiro de Caxangá" (p. 59-63), que João Cabral de Melo Neto faz uma viagem pela estrada de Caxangá preservando, de forma enfática, as marcas da natureza e a própria natureza. 0 sol, aqui, assume a função de sujeito (no caso, homem) para percorrer as veredas e estabelecer relação de intimidade entre sujeito poético e natureza. Da simplicidade, em todos os sentidos, à obscuridade necessária (isto é, exigida pela complexidade do que poeta deseja expressar), a poesia cabralina assume uma abrangência surpreendente, como poucos poetas no Brasil, da geração de 45. Trata-se de um poeta purificado pelo sentimento de um eu poético, ampliado pela conexão com o sentimento do mundo. Nesta perspectiva, percebe-se que João Cabral é dono de uma poética multidimensional que articula a um só tempo muitos conhecimentos. Algumas imagens na sua poesia são misteriosas, quando não obscuras, a exigir do leitor não preparado dificuldade na experimentação: 
A pista de Caxangá

o próprio sol a traçou,

na substância verde e branda

dos engenhos de redor.

Volta

Mas a estrada não pertence

só ao sol aviador.

É também porto de mar

do Sertão do interior.

Possui hotéis para burros,

hospitais para motor,

cemitérios para bondes,

fábricas para o suor.

Mais tudo o que deve haver

num bom porto de vapor:

armazéns, contrabandistas,

fortalezas, guarda-mor.

Ida

Na estrada de Caxangá

tudo passa ou já passou:

o presente e o passado

e o passado anterior;

os engenhos de outros tempos,

de que só nome ficou;

os sítios de casas mansas,

que agonizam sem rancor;

os quintais de sombra doce

com frutas do mesmo teor,

onde hoje carrocerias

aguardam seus urubus. 


\author{
Mas na estrada de Caxangá \\ nada de vez já passou: \\ o verde das canas sobra \\ nos campos de futebol \\ e ainda nas oficinas \\ poças do antigo frescor \\ dos quintais sobram nas úmidas \\ manchas de óleo de motor: \\ que a estrada é também a cauda \\ por onde, ainda em vigor, \\ o Recife arrasta as coisas \\ que do centro eliminou.
}

Ida

Na estrada de Caxangá,

depois que a inaugura o sol,

pares os mais estranhos

todo o dia passam por;

pares como o da raposa

casada com o rouxinol

ou o dos bondes circulando

por entre carros de boi;

caminhões entre galinhas

calam ferralha e furor

e sempre se vê um vaqueiro

olhando um taco de golf.

Volta

Mas na estrada de Caxangá

nem tudo tem tal teor;

por ela passa também

uma gente mais sem cor: 


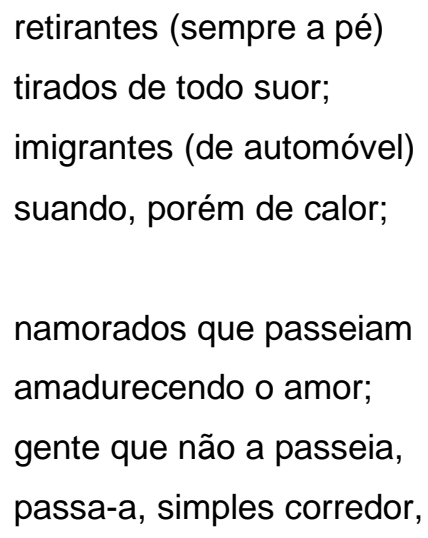

Ida

\author{
A estrada de Caxangá \\ é também trilhos do sol \\ (que nem sempre tem o sol) \\ urgências de aviador): \\ de cada lado dos quais \\ um trem de taipa parou, \\ um trem de casas que lembram \\ vagões, sem tirar nem pôr; \\ um trem de casas-vagões \\ cada um com sua cor \\ e levando nas janelas \\ latas por jarros de flor.
}

Volta

Mas o trem de casas-vagões

passa ou é passado por?

como poder distinguir

do passado o passador?

se na estrada tudo passa

e nada de vez passou?

como saber se é a gente

ou as casas-trem o andador?

ou quem sabe? a própria estrada 
rolando com um propulsor?

(pois dela sobe incessante

e subterrâneo rumor).

Assim como em toda sua obra, o poeta revela-se senhor de uma poesia reflexiva e filosófica, que não para de ir em busca dos aspectos obscuros de nossos pequenos e grandes problemas existenciais e desmascara as aparências falsas da vida que não dão paz ao leitor e ao poeta. Agora, estamos diante de uma poesia de influência espanhola: "A palo seco" (p. 67-72), que, segundo Antonio Carlos Secchin (1983, p. 152), "a ênfase recairá no espaço cultural (e nas implicações estéticas) do cante ' $A$ palo seco'. $O$ texto se divide em quatro segmentos: 1) definição do cante; 2) relação entre o cante e o silêncio; 3) redefinição do cante; 4) exemplificação de situações de objetos a palo seco".

Trata-se de uma poesia purificada pelo sentimento de um eu poético, cujo apresenta diversos recursos sonoros, ampliado pela conexão com o sentimento do mundo e com a necessidade do poeta em definir o que seja cante. Nesta perspectiva, percebe-se que:

\subsection{Se diz a palo seco}

o cante sem guitarra;

o cante sem; o cante;

o cante sem mais nada;

se diz a palo seco

a esse cante despido:

ao cante que se canta

sob o silêncio a pino. 
João Cabral de Melo Neto possui uma poética multidimensional em A palo seco 1.2 a qual articula a um só tempo muitos conhecimentos. Algumas imagens na sua poesia são devassadoras, quando não obscuras, desertas. Note nestes versos o jogo fundamental para a riqueza formal estabelecida pelo poeta por meio de um recurso sintático: o do uso da repetição de certos termos:

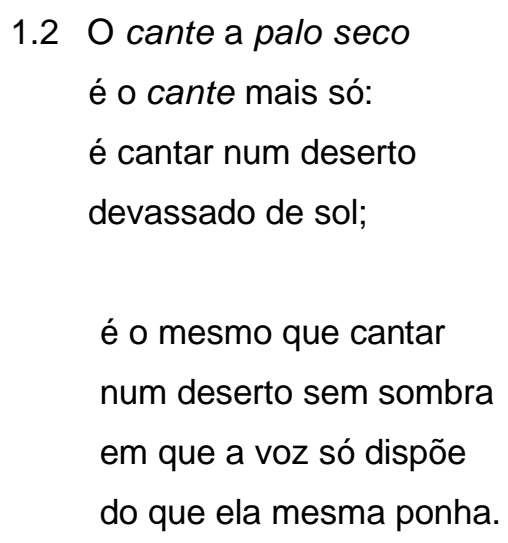

Para Antonio Carlos Sechin (1983, p. 153), "A semelhança entre o itinerário e a caracterização do cante não deve ocultar uma diferença básica: nada mais, em João Cabral, remete à tentação de silêncio de que padecera o personagem da fábula". Evidencia-se assim um lirismo meditativo e seco, em que a evocação da natureza articula a simplicidade de uma linguagem profunda e filosófica. Nesse sentido, verifica-se que a construção do texto depende não apenas da estruturação sintática, mas também da disposição das palavras sobre o papel.

\footnotetext{
1.3 O cante a palo seco é um cante desarmado: só lâmina da voz sem arma do braço;

que o cante a palo sem tempero ou ajuda tem de abrir o silêncio com sua chama nua.
} 
Os cantes cabralino são objetos oferecidos ao leitor, asseverando uma gama muito apurada e reflexiva. Verifica-se, assim, uma imensa vontade em derrotar o silêncio. Suas múltiplas faces retratam o cantar $x$ o calar da condição humana. O poeta evidencia ainda uma forma imagística a qual tece o poema, não hesitando em buscar o discurso lírico. Tudo isso sem perder de vista os diversos recursos sonoros:

O cante a palo seco não é um cante a esmo:

exige ser cantado

com todo o ser aberto;

é um cante que exige

o ser-se ao meio-dia,

que é quando a sombra foge

e não medra a magia.

2.1 O silêncio é uma metal

de epiderme gelada, sempre incapaz das ondas imediatas da aguas;

a pele do silêncio pouca coisa arrepia: o cante a palo seco de diamante precisa.

2.2 Ou o silêncio é pesado, é um liquido denso, que jamais colabora nem ajuda com ecos;

mais bem, esmaga o cante

e afoga-se, se indefeso:

a palo seco é um cante submarino ao silêncio. 
João Cabral de Melo Neto é, reconhecidamente, um dos mais consistentes poetas brasileiros, do século XX. A consistência de sua obra evidencia-se, entre outras coisas, pelo rigor formal e pela utilização e domínio de uma gama muito variada de recursos técnicos, ajustados de forma singular à composição de cada um de seus poemas. Trata-se, portanto, de um poeta fundamental, situado como nome de referência para uma geração importante de poetas. Nesse sentido, este trabalho conclui-se como mais uma contribuição no sentido de realçar a relevância da riqueza formal de um poeta que, ao longo das últimas quatro décadas, tem inspirado gerações de poetas, no Brasil e no mundo. 


\section{REFERÊNCIAS}

BOSI, Alfredo. O ser e o tempo da poesia. São Paulo, Cultrix, 1983.

BRASILEIRO, Antonio. Da inutilidade da poesia. Feira de Santana, UEFS Editora / 7 Letras.

ELIOT, T.S. A essência da poesia. Rio de Janeiro, Artenova, 1972.

MAY, Rollo. A coragem de criar. 11aㅡ ed. Rio de Janeiro, Nova Fronteira, 1982.

PAZ, Octavio. O arco e a Lira. $2^{ }$ed. Rio de Janeiro: Nova Fronteira, 1982.

PEREYR, Roberval. A unidade primordial da lírica moderna. $2^{\mathrm{a}}$ ed. Feira de Santana, UEFS, 2000.

POUND, Ezra. Abc da literatura. $2^{\circ}$ ed. São Paulo, Cultrix, 1934.

SECCHIN, Carlos Antonio. João Cabral: A poesia do Menos. Rio de Janeiro, Livraria Duas Cidades, 1985.

STAIGER, Emil. Conceitos Fundamentais da Poética. Rio de Janeiro, Biblioteca Tempo Universitário, 1969. 